\title{
Oculoosteocutaneous syndrome
}

INSERM

\section{Source}

INSERM. (1999). Orphanet: an online rare disease and orphan drug data base.

Oculoosteocutaneous syndrome. ORPHA:2713

Oculoosteocutaneous syndrome is characterised by congenital anodontia, a small maxilla, short stature with shortened metacarpals and metatarsals, sparse hair, albinoidism and multiple ocular anomalies. It has been described in three siblings (one brother and two sisters). Transmission is autosomal recessive. 